\title{
Climate and weather of the Southern Urals and their influence on agronomy
}

\author{
Yu.M. Nesterenko ${ }^{1}, N . V$. Solomatin ${ }^{1, *}$, and A.V. Khalin ${ }^{1}$ \\ ${ }^{1}$ The Orenburg Federal Research Center of the Ural Branch of the Russian Academy of Sciences, \\ Department of Geoecology, 460014 Orenburg, Russia
}

\begin{abstract}
Changes in climate, precipitation and air temperature in the Southern Urals over the past 133 years are considered. A decrease in the climatic norm of atmospheric precipitation by $24 \mathrm{~mm}$ and an increase in the air temperature in the region by $1.2^{\circ} \mathrm{C}$ were revealed. The main decrease in precipitation occurred during the growing season of early crops, and air temperatures in the autumn-winter period, which significantly changed the conditions for agronomy. The increasing aridity of the climate has worsened the conditions for growing spring crops. The applied system of rain-fed agriculture in Orenburg region provides the use of only $30-40 \%$ of annual precipitation. Early winter sowing of spring wheat in frozen ground with snow cover up to $10-15 \mathrm{~cm}$ is proposed. With them, seed germination, seedlings and tillering of plants are well provided with moisture and have favorable temperature conditions in April-May. Plants with a strong root system can get soil moisture up to 1.5 meters deep and effectively use small precipitation in June and July, which mainly moisturizes the soil to a depth of $5 \mathrm{~cm}$. Early winter sowings of spring wheat are less susceptible to droughts, Favorable soil moisture and air temperature in the spring provide early shoots, plant development and 1.5-2-fold increase in yield. With early winter sowings, the efficiency of using annual precipitation increases to $50-55 \%$.
\end{abstract}

\section{Introduction}

Agronomy is based on natural conditions. They determine the structure of crops and agricultural techniques for their cultivation. The basis of the nature of a particular territory is the geological environment, climate and weather. Together, they form the environment for the biosphere and nature management [1].

Geological environment and its formed relief are the most stable. The geological environment has created an environment in which climate and weather manifest their effect. They are interconnected. Their main indicators are precipitation and air temperature, which affect other indicators of the state of the atmosphere and the earth's surface. However, there are significant differences between them.

\footnotetext{
${ }^{*}$ Corresponding author: geoecol-onc@mail.ru
} 
Climate is an average long-term statistical indicator, over many decades, of the weather regime in a particular area on Earth, which is one of its geographical characteristics [2,3]. Unlike climate, weather is an instantaneous state of the atmosphere: temperature, humidity, precipitation, atmospheric pressure, and other indicators that characterize it. Weather indicators differ from the climate norm, but their deviations from it cannot be considered as climate change. For example, a very hot summer in a particular year can't indicate a climate warming.

Long-term weather conditions that are characteristic of a particular area on the Earth and are one of its geographical characteristics. At the same time, a multi-year regime refers to the totality of all weather conditions in a given area over a period of several decades; the typical annual change of these conditions and possible deviations from it in individual years; combinations of weather conditions characteristic of its various anomalies (droughts, rainy periods, cooling periods, etc.) [3].

The climate of the steppe zone of the Southern Urals is characterized by a deficit coefficient of moisture evaporation from 0.3 to 0.7 . As a result, natural vegetation and cultivated plants in agrocoenosis during the growing season develop mainly in conditions of insufficient moisture supply. We found that the lack of precipitation in relation to evaporation becomes a system-forming component in the formation and development of nature, society, and economy $[1,4]$. As a result, natural biocoenosis are formed mainly from drought-resistant plants.

The article considers the system of agriculture used in the Orenburg region, designed mainly for the use of precipitation in May-July (30\% of the annual norm), which provides an average of about $1 \mathrm{t} / \mathrm{ha}$ of grain crops. It was concluded that it is expedient and possible to increase the efficiency of using annual precipitation up to $50-55 \%$ due to early winter sowings of spring grain crops proposed by us. In cooperation with a number of farms in the region, production early winter sowings of spring wheat gave a 1.5-2-fold increase in yield compared to its spring crops.

\section{Materials and methods of research}

It contains information about the nature of the water-deficient Southern Urals according to research by the authors of the article [1,4], literature sources and stock materials [5], physiological features of spring grain crops and their growing conditions during spring and early winter sowings. In field crops, soil moisture and temperature, snow cover height were measured using the methods of Russian Meteorological Service (Roshydromet) [6]. The yield of spring wheat crops on farms with an area of at least 10 ha and a total area of more than 2000 ha was determined by the results of continuous combine harvesting, and the biological yield on accounting sites with analysis of sheaf material according to the method of B.A. Dospekhov [7]. The yield of spring wheat in early winter sowings in 2019 on an area of 1020 hectares was $13.9 \mathrm{c} / \mathrm{ha}$, in spring $-4.7 \mathrm{c} / \mathrm{ha}$. In early winter sowings of spring wheat, it is $9.7 \mathrm{c} /$ ha higher than in spring sowings at $\mathrm{LSD}_{0.95}-3.5 \mathrm{c} / \mathrm{ha}$ and at $\mathrm{LSD}_{0.99}-5.1$ c/ha.

\section{Results of the study and discussion}

Climate and weather issues have been of concern to mankind for hundreds of years. The problem of their forecast has been solved by scientists for many decades [8,9]. Special attention is paid to climate warming and the impact of anthropogenic activities on it [1013]. The Southern Urals, located in the center of the Eurasia, is characterized by a continental climate with large fluctuations in precipitation and air temperature over the 
years and its periods. We have made an attempt to analyze its climate and weather in conditions of significant changes in the planet's climate.

Precipitation is not evenly distributed across the region. In the southern part of the Southern Urals, the average precipitation is less than $350 \mathrm{~mm}$ per year, and the moisture coefficient is less than 0.45 . As a result, there was formed a semi-desert habitat with a predominance of wild rye, sheep fescue and wormwood, as well as ephemeral plants. Lowgrowing forest vegetation is found only in the floodplains of small rivers. With an increase in the availability of atmospheric precipitation up to $400 \mathrm{~mm}$ per year in the middle part of the Southern Urals, more moisture-demanding plants (wheatgrass, feather grass, awnless brome grass, and others) appear in natural biocoenosis. Forest cleavages appear along the relief depressions, increasing the forest cover up to $3-4 \%$. In the Northern part of the region, the amount of precipitation increases $450-500 \mathrm{~mm}$ per year, and the moisture coefficient is up to 0.6-0.7. This allows for the formation of more moisture-loving forbfeather grass biocoenosis. High-stemmed tree species (birch, oak, poplar) appear. Forest cover increases to $15-25 \%$.

In the conditions of relatively high availability of heat resources in the Southern Urals, the significance of changes in precipitation as a climatic factor and as a short-term weather factor in different periods increases. Based on the data of the Roshydromet, the main components of its climate, precipitation and air temperature that most affect the agronomy of the region are considered. Figure 1 shows data on the annual amount of precipitation and air temperature in the steppe zone according to the weather station in the Orenburg region in 1887-2019. The 133-year period under study is sufficient to analyze its climate.

The linear function of precipitation and air temperature characterizes them as climatic components of the region's nature. At the beginning of the analyzed period in 1887, the linear function of atmospheric precipitation according to its formula had a value of 377 $\mathrm{mm}$, which corresponds to the average annual amount on this date. Calculations using the linear trend formula showed that after 133 years, with an average decrease of 0.1768 $\mathrm{mm} /$ year, in 2019, the average amount of precipitation is $353 \mathrm{~mm} /$ year. Consequently, in the region of the city of Orenburg for 133 years, the average amount of precipitation decreased by $24 \mathrm{~mm} /$ year, $6.4 \%$ less than in 1887 . Analysis of the linear function of air temperature showed that at the beginning of the analyzed period in 1887 , the average annual temperature was $+3.4{ }^{\circ} \mathrm{C}$, and by 2019 it had increased to $+5.7^{\circ} \mathrm{C}$.

A joint analysis of linear trends in precipitation and air temperature over a 133 -year period that characterize the climate shows a gradual increase in its aridity with a rapid increase in annual air temperature. The causes of climate warming in the Southern Urals are obviously global climate processes. Its climate, like that of the whole of the Europe, largely depends on the state of the Central and North Atlantic. Its warming led to increased melting of Greenland's glaciers and a decrease in the ice area of the Western Arctic ocean [10]. The prevailing transfer of air masses from West to East on the European continent caused climate warming in the Southern Urals. Anthropogenic influence on the climate is not excluded.

Unlike gradual changes in climate, precipitation, and air temperature, they deviate significantly from the climate trend line over the years, forming the weather of the year or its periods.

The analysis of weather dynamics in the 133-year period under study is based on polynomial trend lines. In our opinion, the 5 and 6 degree polynomial lines are the most informative for the analyzed period (Fig. 1). Their deviations from the linear climate trend show the presence of long-term evolutionary changes. These changes can also be considered as weather conditions cyclicity, which together determine the position of the linear climate trend line. 
In 1887-1893, precipitation was less than normal $(292 \mathrm{~mm})$. In the following years, 1894-1922, they were on average higher than normal (409 mm), and then until 1968 they became lower $(350 \mathrm{~mm})$. From 1969 to 2010 , the average annual precipitation is close to the climatic norm $(373 \mathrm{~mm})$, which is gradually decreasing. In the last decade, there has been a significant decrease $(343 \mathrm{~mm})$.

A similar analysis of linear trends in annual air temperatures over the 133-year period under study (Fig. 1) also revealed their cyclical nature. In 1887-1904, the average air temperature is higher than the linear climate trend $\left(+3.8^{\circ} \mathrm{C}\right)$.
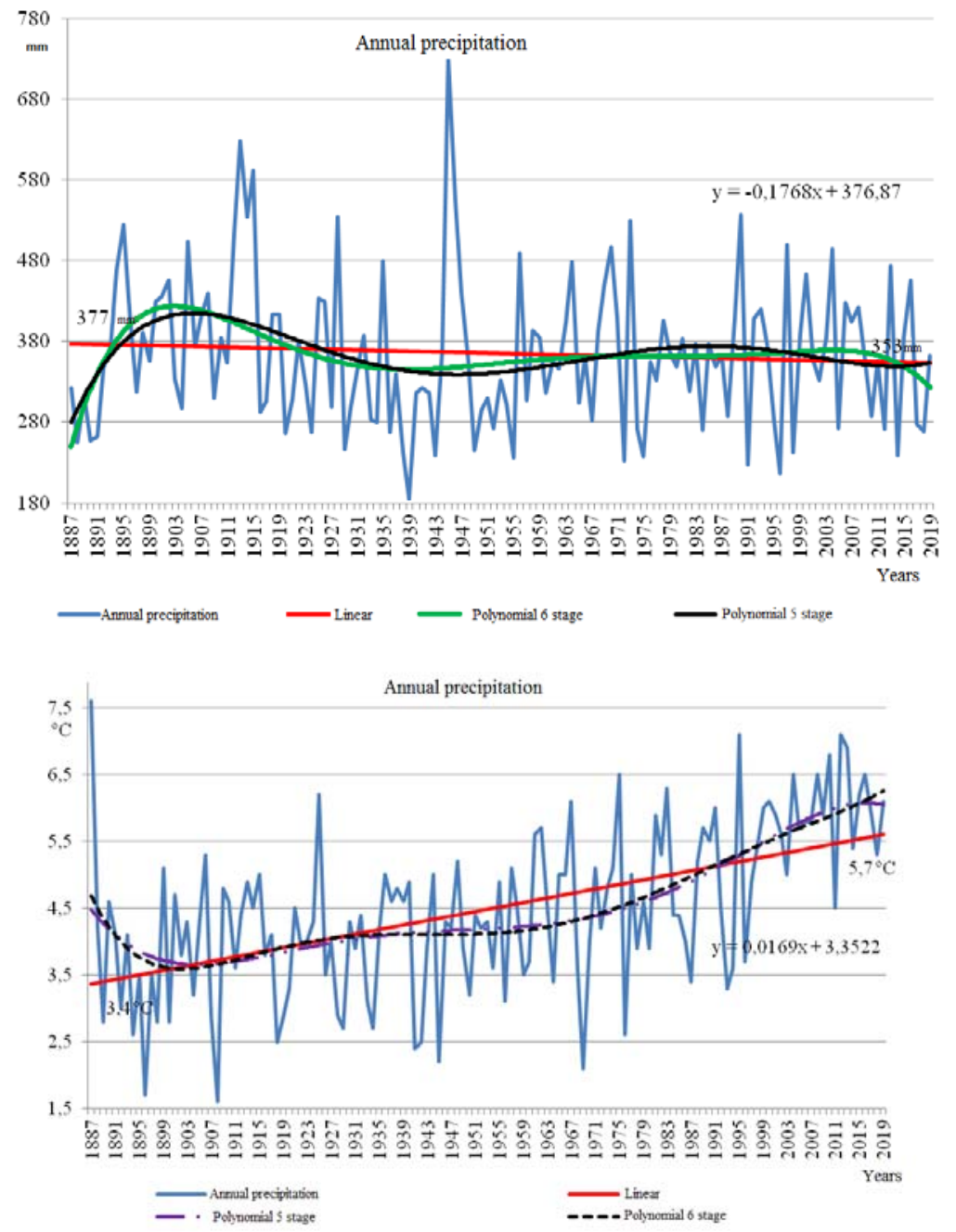

Fig. 1. Characteristics of climate (linear trend) and weather conditions (polynomial trends) in the city of Orenburg in 1887-2019. Characteristics of climate (linear trend) and weather conditions (polynomial trends) in Orenburg in 1887-2019. On the X-axis - Years; on the Y-axis - Precipitation or Temperature]

Further, according to the trends of 5 and 6 degrees, until 1932, there followed a period of average temperature variation close to the climatic norm of this period $\left(+4.0{ }^{\circ} \mathrm{C}\right)$, which provides a gradual average long-term increase of $0.0169{ }^{\circ} \mathrm{C}$ per year. The next 60 years until 1993 are characterized by a lower average air temperature in relation to the linear 
climate trend, but rising with it up to $+4.4^{\circ} \mathrm{C}$. In the period from 1993 to 2019 , there is a relatively rapid increase in the average annual air temperature up to $+5.8{ }^{\circ} \mathrm{C}$, causing an additional high rate of its increase as a climate indicator.

The values of annual precipitation and air temperature in the 133-year period under study significantly deviate from the climatic norm. The maximum (1945) and minimum (1939) amounts of annual atmospheric precipitation are 2 times, respectively, more or less than the climatic norm of these years. Analysis of deviations in annual air temperatures showed that the maximum (1925) values are 1.5 times higher than the climate norm, and the minimum (1908 and 1969) are 2.2 times less than the climate norm. Large deviations of annual precipitation and temperatures from the climatic norm significantly affect the productivity of the biosphere, economy and society of the region [4].

For the society, economy, and especially crop production in the water-deficient Southern Urals, information about climate changes by period of the year is important. Fig. 2 presents information on the amount of precipitation in the autumn-winter in October-March (X-III) and the growing season in May-July (V-VII) of early spring grain crops that predominate in the Southern Urals.

The trend line of precipitation in the autumn-winter period shows that their climatic norm, as well as the annual one, decreases by $0.0692 \mathrm{~mm} /$ year. As a result, their average number of $173 \mathrm{~mm} /$ year in 1887 decreased by $9 \mathrm{~mm}(-5.2 \%)$ over 133 years, and by 2019 their climate norm in X-III decreased to $164 \mathrm{~mm} / \mathrm{year}$. The rate of decrease in autumnwinter precipitation is $1.2 \%$ lower compared to the annual norm, which indicates an increase in their share in the average annual precipitation balance. However, they are more cyclical than the annual climate trend. In 1887-1911, precipitation was less than the climatic norm. In 1912-1920, the trend lines of degree 5 and 6 were higher than the linear trend that characterizes the climate, and then until 1968, precipitation in the autumn-winter period fell less than the climatic norm. The increased amount of precipitation in1969-2004 was replaced by the amount close to normal with a tendency to decrease.

The analysis of climatic conditions of vegetation of early spring grain crops in V-VII by atmospheric precipitation in the Orenburg region is made based on the data of Fig. 2. Their trend line, which characterizes the climate of this period of the year in the studied years 1887-2019, shows that the climatic norm of atmospheric precipitation, as well as the annual one, decreases by $0.1321 \mathrm{~mm} /$ year. As a result, their average number of $122 \mathrm{~mm} /$ year in 1887 for 133 years decreased by $18 \mathrm{~mm}(-15 \%)$ and by 2019 their climate norm in V-VII decreased to $104 \mathrm{~mm} /$ year. The rate of precipitation reduction in the studied vegetation period is $9 \%$ higher compared to the annual norm and $10 \%$ higher compared to the autumnwinter period, which indicates a significant decrease in their share in the average annual balance of precipitation and a significant change in the vegetation conditions of plants in natural biocoenosis and on arable land. The analysis of temperature conditions in the Orenburg region in the autumn-winter and vegetation period according to Fig. 3 revealed a faster increase in temperature in the cold season by $2.8^{\circ} \mathrm{C}$, from $-8.6^{\circ} \mathrm{C}$ in 1887 to $-5.8^{\circ} \mathrm{C}$ in 2019 in the summer period (V-VII), it increased only by $1.1^{\circ} \mathrm{C}$ up to $19.6^{\circ} \mathrm{C}$.

The climate and weather of the Southern Urals and changes in them significantly determine its agronomy. At present, in comparison with 1887, the climatic norm of atmospheric precipitation has decreased by $18 \mathrm{~mm}(-15 \%)$ to $104 \mathrm{~mm} /$ year, with an increase in temperature by $1.1{ }^{\circ} \mathrm{C}$. A decrease in precipitation and an increase in air temperature during the growing season of spring crops in V-VII make it necessary to adapt agronomy, its farming system, crop structure and crop cultivation technologies to climate changes. Objectively, there is a need to improve the efficiency of using precipitation in other periods of the year.

According to the climate trend (Fig. 2), at present, $164 \mathrm{~mm}$ of them fall in the autumnwinter period, which is $46 \%$ of the annual norm and $37 \%$ more than their number during 
the growing season of early grain crops, which occupy more than $60 \%$ of the arable land area of the Orenburg region. Its main crop is spring wheat sown on an area of about 2.5 million hectares ( $57 \%$ of arable land).

With the applied technology of spring sowing of spring wheat, after harrowing and drying the soil to a humidity favorable for the operation of sowing units, up to 80-100 $\mathrm{mm}$ of spring moisture reserves accumulated in the soil due to autumn-winter precipitation is unproductively physically evaporated. As a result, the main sources of moisture for early grain crops are mainly precipitation in May-July with partial use of spring reserves, which leads to low yields. In the farms of the Orenburg region in 2009-2019, the average yield of spring wheat is $6.6 \mathrm{c} /$ ha with fluctuations from $1.4 \mathrm{c} /$ ha in 2010 with $14 \mathrm{~mm}$ of precipitation in May-July to $11.6 \mathrm{c} /$ ha with $121 \mathrm{~mm}$ of precipitation. The annual precipitation in these years is less than the long-term average, $287 \mathrm{~mm}$ and $277 \mathrm{~mm}$, respectively, but which can ensure the yield of early grain crops up to $20 \mathrm{c} / \mathrm{ha}$. Therefore, it is necessary to develop an agronomy system that ensures efficient use of all annual precipitation.

The phrasing of V.I. Michurin "We cannot wait for favors from nature; it is our task to take them from her" [14] is well-known. Further, continuing, he said: "But nature must be treated with respect and care and, if possible, its original form must be preserved". In the case of agronomy, which depends largely on natural conditions, his phrasings will be: "We can't expect favors from nature; we need to use its resources effectively, multiplying them".

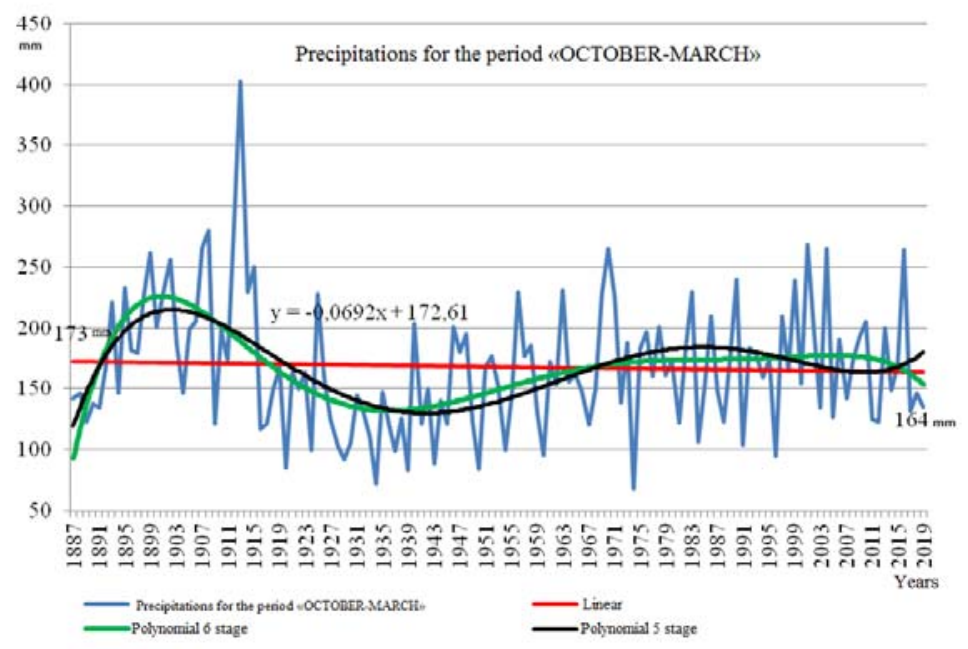




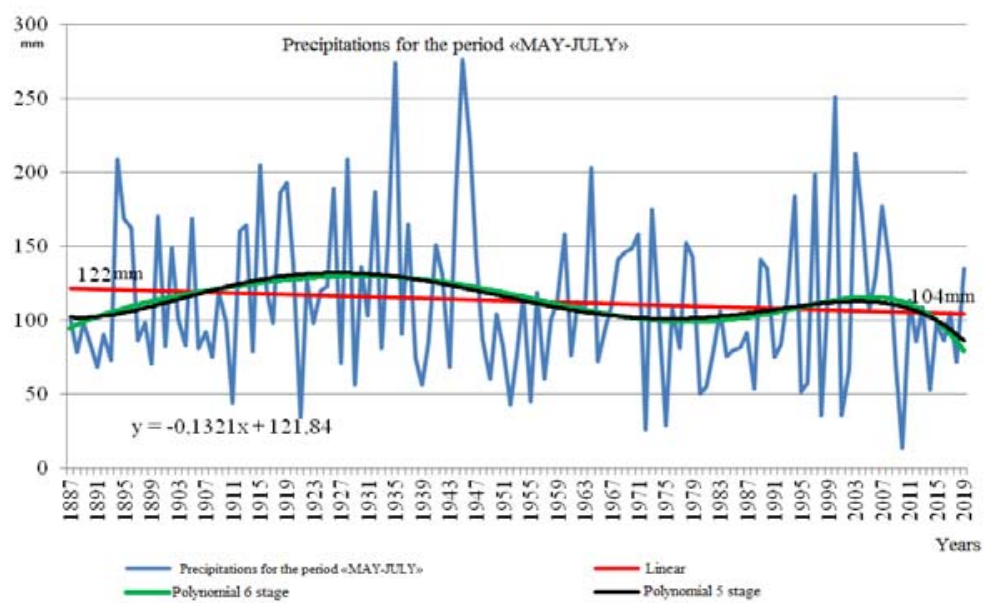

Fig. 2. Characteristics of the climate (linear trend) and weather conditions (polynomial trends) by atmospheric precipitation of the autumn-winter and vegetation periods in the city of Orenburg in 1887-2019. [Fig. 2. Characteristics of the climate (linear trend) and weather conditions (polynomial trends) by air temperature of the autumn-winter and vegetation periods in Orenburg in 1887-2019. On the X-axis - Years; on the Y-axis - Precipitation]

For the water-deficient Southern Urals with fertile soils and large thermal resources, the most important thing in agronomy is to increase the efficiency of the use of atmospheric precipitation, the provision of which during the

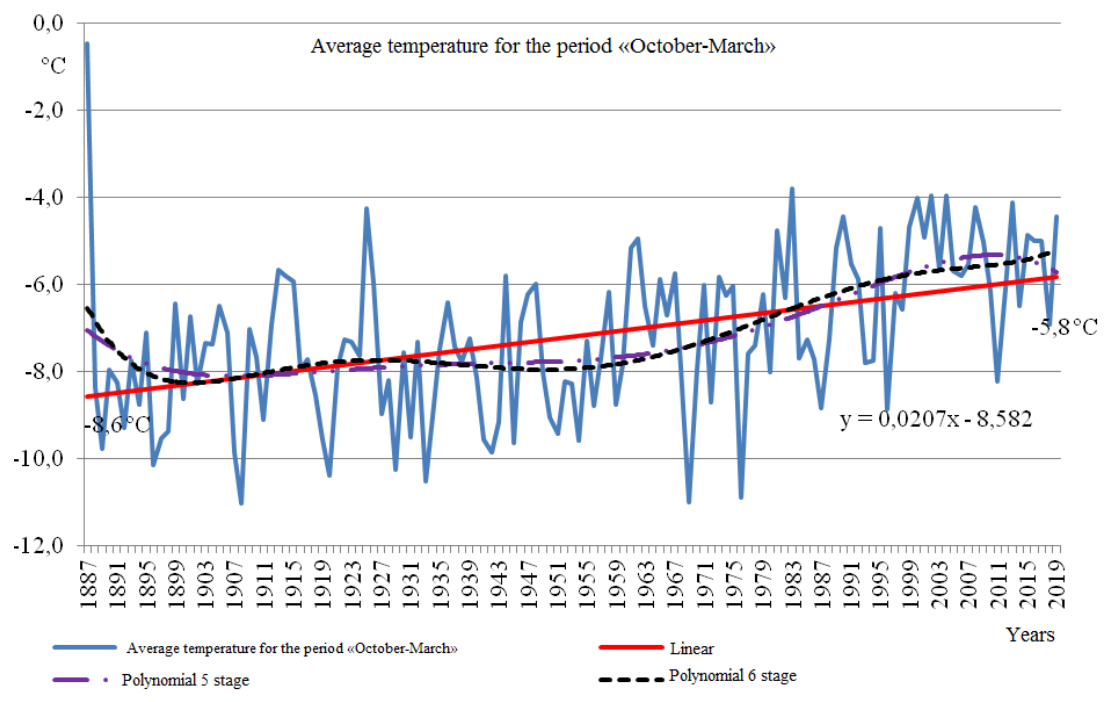




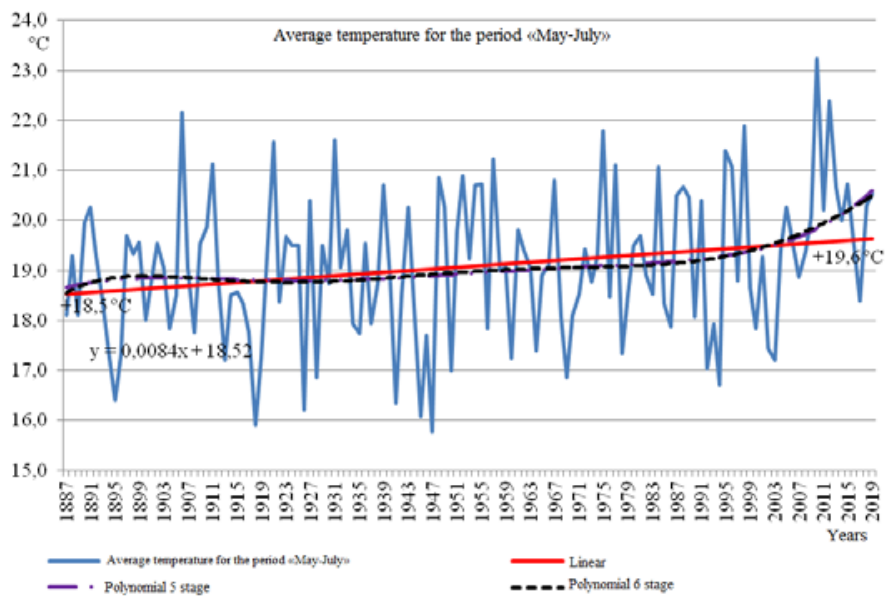

Fig. 3. Characteristics of the climate (linear trend) and weather conditions (polynomial trends) by air temperature of the autumn-winter and vegetation periods in the city of Orenburg in 1887-2019. [Fig. 2. Characteristics of the climate (linear trend) and weather conditions (polynomial trends) by air temperature of the autumn-winter and vegetation periods in Orenburg in 1887-2019. On the X-axis Years; on the Y-axis - Temperature]

growing season of spring grain crops in May-July in terms of evaporation is only 0.25 at an annual rate of 0.50 . The applied system of rain-fed agriculture in the Orenburg region ensures the use of only $30-40 \%$ of annual precipitation and is not focused on their effective use by spring crops. This was the main reason for the low average yield in the Orenburg region. On average, in 1961-2019, the yield of spring wheat in the region was $6.3 \mathrm{c} / \mathrm{ha}$, with a potential yield for precipitation and heat resources of $20-25 \mathrm{c} /$ ha. There is an objective need to develop an agronomic system based on the efficiency of plants' use of the entire annual amount of precipitation, including autumn and winter precipitation [15].

A significant (one and a half to two times) increase in grain yield in the region is possible based on more efficient use of the maximum accumulated precipitation in the soil and its underlying soils in the autumn-winter period after melting of snow. For this, laboratory of water resources in water-stressed areas of the Geoecology Department of Orenburg Science Center of the RAS on the basis of fundamental and applied research of the natural components of the steppe Southern Urals and biological properties of agricultural crops, suggests sowing a number of grain crops in late autumn and early winter in freezing and frozen soil with a snow cover up to $10 \mathrm{~cm}$ and more [16]. With early winter sowings, the efficiency of using annual precipitation increases to $50-55 \%$. In three-year experiments of early winter sowing of spring wheat, we have identified its good shoots and subsequent development. Seed germination, seedlings and tilling of plants are well provided with moisture and have favorable temperature conditions in April-May. Welldeveloped plants with a strong root system can consume soil moisture up to 1.5 meters deep and effectively use small precipitation in June and July, which moistens the soil mainly to a depth of $5 \mathrm{~cm}$. Early winter sowings of spring wheat are less susceptible to droughts. In experimental production early winter sowings of spring wheat on an area of 100 ha in the acutely arid 2018, 13-15 c/ha of grain was obtained, and in the favorable precipitation 2017 on an area of 18 ha $35 \mathrm{c} / \mathrm{ha}$, which is $1.5-2$ times more than in the neighboring fields of its spring sowing (Fig. 4). 


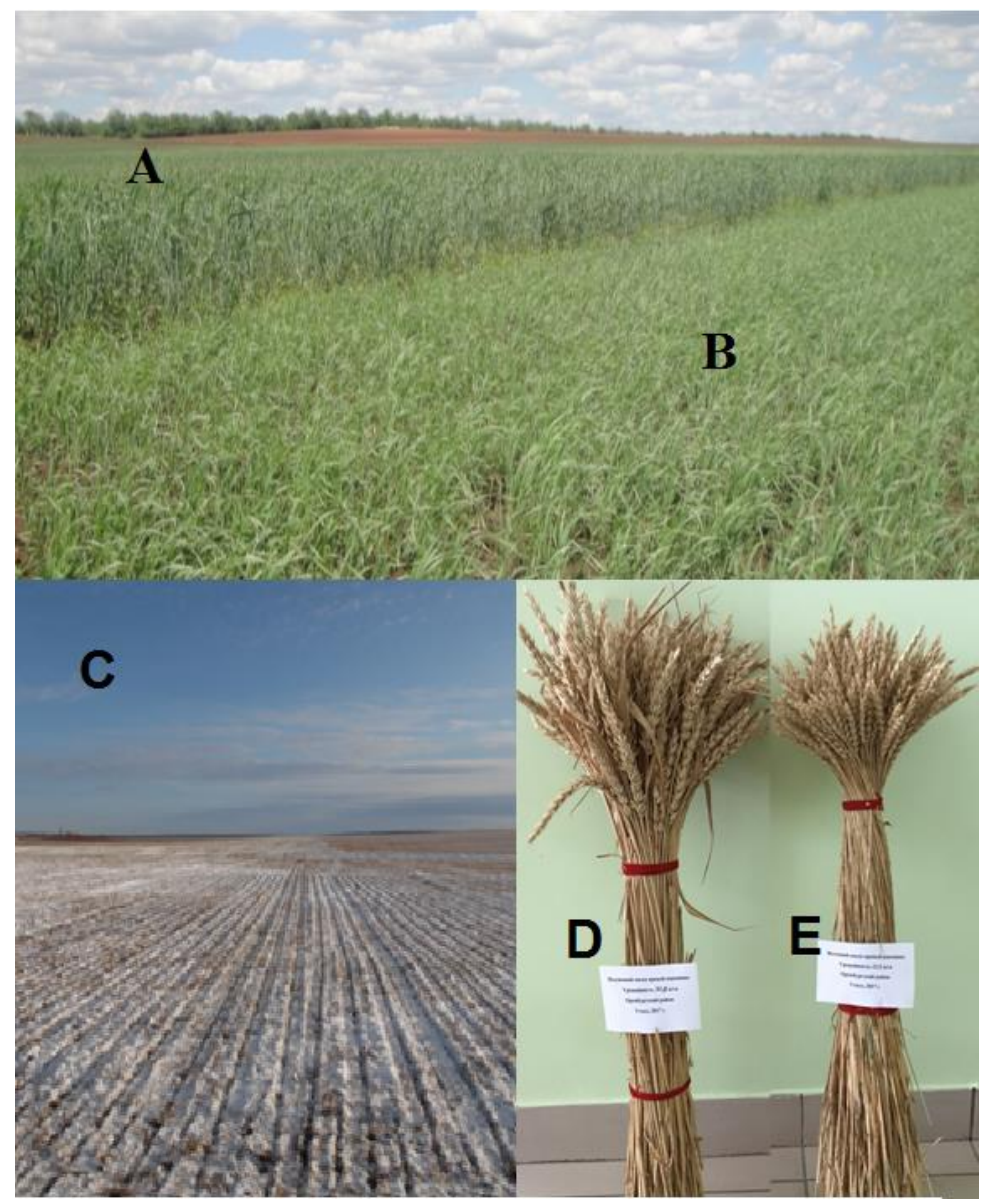

Fig. 4. Crops and sheaf material of spring wheat with different sowing dates (early winter and spring) in 2017 (A - wheat crops in the early winter period, B - wheat crops in the spring, C - wheat crops in frozen soil; D - wheat sheaf of early winter sowing, E - wheat sheaf of spring sowing[Fig. 4. Crops and sheaf material of spring wheat with different sowing dates (winter and spring) in 2017 (A - wheat crops in the winter period, B-wheat crops in the spring, C-wheat crops in frozen soil; D -wheat sheaf of winter sowing, E - wheat sheaf of spring sowing]

In production early winter sowings of spring wheat in farms of the Orenburg region on an area of more than 300 hectares, 13-18 c/ha was obtained in 2019, with an average yield of spring wheat of $5.2 \mathrm{c} / \mathrm{ha}$. The quality of wheat grain under early winter sowing is high. Natural grain weight $-813 \mathrm{~g} / \mathrm{l}$, gluten in the grain $-24.8 \%$.

For the early winter, November-December, sowings of early spring grains and other crops that we have developed, additional research is needed to prepare the soil, ensuring the seeding of seeds to a depth of 1-3 cm into freezing and frozen soil with various sowing units. Due to the significantly increased yield of spring grain crops in comparison with spring crops, it became necessary to review the system of fertilizers, weed control and diseases. Especially important is the issue of expanding the set of agricultural crops of early winter sowing, their varieties and forms with different vegetation periods for more efficient use of precipitation during the winter and growing seasons. It also requires testing and selection of agricultural tools that can work in autumn and winter conditions and meet the requirements of plants for the quality of their work. 
It is necessary to study a number of other problems and technological processes that ensure the effective use of precipitation and soil in the water-deficient steppe Southern Urals. The Department of Geoecology of the OFRC of the Ural Branch of the Russian Academy of Sciences is working on their solution.

\section{Conclusions}

1. Climate aridization is underway in the Southern Urals. Analysis of meteorological observations in the city of Orenburg for 1887-2019 revealed a decrease in the average annual precipitation for 133 years by $24 \mathrm{~mm}$ to $353 \mathrm{~mm} /$ year and an increase in the average annual air temperature by $2.3{ }^{\circ} \mathrm{C}$.

2. According to the seasons of the year, the greatest decrease in atmospheric precipitation is during the growing season of grain crops. In May-July, for 133 years, the average number of them decreased by $15 \%$ to $104 \mathrm{~mm} /$ year. In the autumn-winter period, the climatic norm of precipitation decreased by $5 \%$ to $164 \mathrm{~mm} /$ year.

3. The climate norm for air temperature for the studied 1887-2019 years during the growing season of agricultural crops increased by $1.1{ }^{\circ} \mathrm{C}$, and in the autumn-winter period by $2.8^{\circ} \mathrm{C}$.

4. The strategy of agronomy, its science and practice, must adapt to climate change in the region. In the conditions of decreasing precipitation in the spring and summer period, it is necessary to increase the efficiency of using precipitation in other periods of the year. The proposed early winter sowings of spring grain crops in the steppe zone in conditions of stable snow cover effectively use autumn-winter precipitation, are less susceptible to droughts and give a 1.5-2-fold increase in yield.

\section{References}

1. Yu.M. Nesterenko, Water component of arid zones: ecological and economic significance (Yekaterinburg: Ural Branch of the Russian Academy of Sciences, 2006)

2. Great Soviet Encyclopedia (M.: Sov. Encyclopedia, 1969-1978)

3. A.P. Gorkin, Geography: Modern pictorial encyclopedia (Rosman, 2006)

4. Yu.M. Nesterenko, M.Yu. Nesterenko, Natural waters of the Southern Urals: formation and use (Yekaterinburg: Ural Branch of the Russian Academy of Sciences, 2016)

5. Statistical Yearbook of the Orenburg region (Orenburg, 2018)

6. Instructions for hydrometeorological stations and posts. Meteorological observations at stations, 3(1) 300 (L.: Hydrometeoizdat, 1985)

7. B.A. Dospekhov, Methodology of field experience (with the basics of statistical processing of research results) (M.: Agropromizdat, 1985)

8. Koppen W. Klimalehre, Mit 7 Tafeln und 2 Figuren, (Leipcig, 1899)

9. M.I. Budyko, Climate and life, (L.: Hydrometeoizdat, 1956)

10. K.S. Losev, Climate: yesterday, today... and tomorrow? Acad. of the Academy of Sciences of the USSR K. Ya. Kondratyev, (L.: Hydrometeoizdat, 1985)

11. J.E. Hansen, A.A. Lacis, Nature, 346, 713-719 (1990)

12. E.J. Chaisson, EOS. The Newspaper of the Geophysical Sciences, 89(28) 253-260 (2008) doi:10.1029/2008eo280001. Bibcode: 2008EOSTr.89. 253 P. 
13. V.A. Mikheev, Classification of climates, Climatology and meteorology (Ulyanovsk: Ulyanovsk State Technical University, 2009)

14. I.V. Michurin, Selected works (Moscow: Moskovsky Rabochy, 1950)

15. Yu.M. Nesterenko, Bulletin of the Orenburg Scientific Center of the Ural Branch of the Russian Academy of Sciences, 3, 15 (2018) (URL: http://elmag.uran.ru:9673/magazine/Numbers/2018-3/Articles/NYM-2018-3.pdf). DOI: 10.24411/2304-9081-2018-13006.

16. A.V. Khalin, F.G. Bakirov, Yu.M. Nesterenko, Bulletin of the Orenburg Scientific Center of the Ural Branch of the Russian Academy of Sciences, 4, 9s. (2019) (URL: http://elmag.uran.ru:9673/magazine/Numbers/2019-4/Articles/HAV-2019-4.pdf). DOI: 10.24411/2304-9081-2019-14009 